\title{
Tumor Protein 53 Gene Mutations Without 17p13 Deletion Have No Significant Clinical Implications in Chronic Lymphocytic Leukemia. Detection of a New Mutation
}

\author{
PANAGIOTIS T. DIAMANTOPOULOS ${ }^{1}$, STAVROULA SAMARA ${ }^{2}$, PANAGOULA KOLLIA ${ }^{2}$, \\ NEFELI GIANNAKOPOULOU ${ }^{1}$, MARIA SOFOTASIOU ${ }^{1}$, FANI KALALA $^{1}$, ELINA KODANDREOPOULOU ${ }^{1}$, \\ PANAGIOTIS ZERVAKIS ${ }^{1}$, THEODOROS VASSILAKOPOULOS ${ }^{1}$, MARINA SIAKANTARIS ${ }^{1}$, \\ MARINA MANTZOURANI ${ }^{1}$, MARIA ANGELOPOULOU ${ }^{1}$, MARIE-CHRISTINE KYRTSHONIS ${ }^{1}$, \\ PENELOPE KORKOLOPOULOU ${ }^{3}$, EFSTATHIOS PATSOURIS ${ }^{3}$ and NORA-ATHINA VINIOU ${ }^{1}$ \\ ${ }^{1}$ First Department of Internal Medicine, Hematology Unit, \\ National and Kapodistrian University of Athens, Laikon General Hospital, Athens, Greece; \\ ${ }^{2}$ Department of Genetics \& Biotechnology, Faculty of Biology, School of Physical Sciences, \\ National and Kapodistrian University of Athens, Athens, Greece; \\ ${ }^{3}$ Department of Pathology, National and Kapodistrian University of Athens, Athens, Greece
}

\begin{abstract}
Background: The tumor protein p53 (TP53) gene may be inactivated through $17 p 13$ deletion, somatic mutations, or both. In chronic lymphocytic leukemia (CLL) although $17 p 13$ deletion is correlated with poor prognosis, the role of sole TP53 mutations remains controversial. Materials and Methods: We carried out a mutation analysis of TP53 gene in 72 patients with CLL. Results: Seventy-one (98.6\%) patients carried the polymorphic site c. $215 C>G$, p.Pro72Arg, but its presence was not correlated with overall survival (OS). Moreover, 19 (26.4\%) patients carried a mutation of TP53. Among the eight detected mutations, to our knowledge, one (c.587G>A) has never been reported in the past. There was a correlation of the mutation burden with the stage of the disease $(p=0.022)$, but not with OS. None of the detected mutations was individually correlated with OS. Conclusion. The clinical significance of TP53 mutations is still a matter of debate and larger studies and meta-analyses are required to reach an unequivocal conclusion.
\end{abstract}

\footnotetext{
Correspondence to: Panagiotis Diamantopoulos, MD, Ph.D., First Department of Internal Medicine, National and Kapodistrian University of Athens, Laikon General Hospital, Athens 11527, Greece. Tel: +30 2132061843, Fax: +30 2132061795, e-mail: pandiamantopoulos@gmail.com
}

Key Words: Tumor protein 53, chronic lymphocytic leukemia, mutation analysis, prognosis.
A functional p53 protein is essential for the maintenance of the genetic integrity of a healthy cell and for the cytotoxic effect of DNA-damaging chemotherapy drugs on neoplastic cells. The clinical importance of abnormalities of its encoding gene, TP53, in chronic lymphocytic leukemia (CLL) has been extensively studied. These abnormalities consist of inactivation of TP53 through $17 \mathrm{p} 13$ deletion, somatic mutations, or both. The clinical significance of $17 \mathrm{p} 13$ deletion detected by fluorescence in situ hybridization (FISH) is unequivocal and the poor prognosis marked by it is well documented in both the chemotherapy and immunochemotherapy era $(1,2)$. This chromosomal abnormality characterizes an advanced-stage, rapidly progressing disease requiring treatment. Deletion of $17 \mathrm{p} 13$ is detected in $4-8 \%$ of patients at diagnosis, $8-11 \%$ at the time the patient requires initial treatment for disease progression, $\sim 30 \%$ in patients with purine-analog-refractory disease (3), and $>40 \%$ in Richter syndrome (4). Almost $70 \%$ of patients with $17 \mathrm{p} 13$ deletion also harbor TP53 mutations (5), while $17 \mathrm{p} 13$ deletion without TP53 mutation is much less frequent $(\sim 10 \%)$. On the other hand, $20-30 \%$ of patients with TP53 abnormalities carry only mutations and not $17 \mathrm{p} 13$ deletion at the time of diagnosis (6).

The clinical significance of sole TP53 mutations without concomitant $17 \mathrm{p} 13$ deletion remains controversial. Several studies provide data about the prognostic significance of TP53 somatic mutations, but the net result of the research so far is not conclusive.

In a series of 308 newly-diagnosed patients with CLL, multivariate analysis showed that TP53 mutations carry a prognostic value that is independent of $17 \mathrm{p} 13$ deletion since 
patients with TP53 mutations without 17 p13 deletion had a lower overall survival (OS) than patients without TP53 mutations or 17 p13 deletion $(p<0.001)(7)$. Similarly, TP53 mutations were evaluated as independent factors of a poor prognosis in 173 Chinese patients with CLL (8). Another study reported rapid disease progression in patients with CLL harboring isolated TP53 mutations, but this study did not provide survival data for analysis (9).

Several other studies reported a poorer prognosis associated with TP53 mutations, but without testing for the confounding impact of a concomitant $17 \mathrm{p} 13$ deletion $(5,10-12)$.

On the other hand, there are several reports indicating that isolated TP53 mutations do not affect prognosis. Thus, in a study where isolated TP53 mutations were detected in $7.6 \%$ out of a total of 529 patients with CLL, there was no correlation with progression-free survival or OS (13). Moreover, in a study on 99 patients with fludarabinerefractory CLL, where $39 \%$ of the patients carried TP53 mutations ( $18 \%$ without $17 \mathrm{p} 13$ deletion), there was no correlation of TP53 mutation with survival (14).

Most TP53 mutations occur in exons 4-9 and frequently disrupt the DNA-binding domain of the protein (15). Thus, the majority of the reports so far refer to studies on exons 4 to 9 , with or without exons 2 and 3 . Nevertheless, about $20 \%$ of the mutations occur in introns.

In order to contribute to this field, we present the results of a mutation analysis of the TP53 gene in patients with CLL. The results of the analysis were correlated with the epidemiological and hematological characteristics of the patients, as well as their prognosis.

\section{Materials and Methods}

A consecutive series of 72 patients with CLL who were treated at our Center from June 2008 to June 2014 were included in the study. The patients were followed-up from diagnosis; six patients were lost to follow-up. All patients provided informed consent and the diagnosis of CLL was confirmed by flow cytometry in all cases. All patients had peripheral blood disease by flow cytometry at the time of sample collection.

We recorded the following variables at sample collection: (a) age, sex, date of diagnosis; (b) Binet stage at diagnosis and at sample collection; and (c) peripheral blood lymphocyte count, hemoglobin level, platelet count, lactate dehydrogenase (LDH) and $\beta 2$ microglobulin levels. Date of last contact and survival status during last contact were also recorded.

FISH for $17 \mathrm{p} 13$ deletion was carried out according to the treating physician's decision (at diagnosis, disease progression, or treatment failure) and not at baseline in all cases. Thus, FISH for $17 \mathrm{p} 13$ deletion was carried out in 28 (38.9\%) patients.

Peripheral blood samples were drawn in EDTA and DNA extraction was performed using standard procedures within 6 hours from collection. DNA was then stored at $-20^{\circ} \mathrm{C}$. The TP53 gene sequences from exons 4, 5-6, 7 and 8-9 were amplified by polymerase chain reaction (PCR) according to the instructions outlined in http://p53.iarc.fr/ProtocolsAndTools.aspx (accessed on
Table I. Patient characteristics.

\begin{tabular}{|c|c|}
\hline Parameter & Value \\
\hline Number of patients, $\mathrm{N}(\%)$ & $72(100)$ \\
\hline Male to female ratio & 1.48 \\
\hline Median age (range), years & $70(37-91)$ \\
\hline \multicolumn{2}{|l|}{ Stage (Binet), $N(\%)$} \\
\hline \multicolumn{2}{|l|}{ At diagnosis } \\
\hline A & $34(47.2)$ \\
\hline B & $20(27.8)$ \\
\hline $\mathrm{C}$ & $16(22.2)$ \\
\hline \multicolumn{2}{|l|}{ At sample collection } \\
\hline A & $30(41.7)$ \\
\hline B & $18(25.0)$ \\
\hline $\mathrm{C}$ & $22(30.6)$ \\
\hline TP53 deletion, $\mathrm{N}(\%)^{*}$ & $2(7.1)$ \\
\hline \multicolumn{2}{|l|}{$\begin{array}{l}\text { Median peripheral blood lymphocyte } \\
\text { count (range), } \times 10^{9} / 1\end{array}$} \\
\hline Median hemoglobin (range), g/dl & $13.3(8.3-17.9)$ \\
\hline Median platelet count (range), $\times 10^{9} / 1$ & $168(30-472)$ \\
\hline Median LDH/ULN (range) & $1.1(0.6-7.5)$ \\
\hline Median $\beta 2$-microglobulin/ULN (range) ${ }^{\dagger}$ & $2.6(0.2-11.9)$ \\
\hline TP53 polymorphism (p53Arg), N (\%) & $71(98.6)$ \\
\hline \multicolumn{2}{|l|}{ TP53 polymorphism homozygosity } \\
\hline$(\operatorname{Arg} / \operatorname{Arg}), \mathrm{N}(\%)$ & $47(56.2)$ \\
\hline TP53 mutation, $\mathrm{N}(\%)$ & $19(26.4 .0)$ \\
\hline
\end{tabular}

LDH: Lactate dehydrogenase; ULN: upper limit of normal. *By fluorescence in situ hybridization in 28 patients. †Measured in 38 patients.

March 19, 2017) and re-sequenced to identify the underlying sequence variations. Sequencing was performed twice per sample (two independent PCR products) in both forward and reverse orientations. Genomic DNA information was obtained from GenBank wild-type sequence [TP53: NG_017013.2, NM_000546.5]. Sequence variants/mutations were verified using the MegaBase 1000 DNA Sequencing System (Amersham Biosciences Corp, Piscataway, NJ, USA). The underlying variations in the cohort were detected by multiple alignment sequences using Chromas Lite 2.01 and Chromas Pro 1.5 software (Technelysium Pty Ltd, South Brisbane, Australia) and BLAST[National Center for Biotechnology Information (NCBI), Bethesda MD, USA].

SPSS statistics, v19.0 (IBM, Armonk, NY, USA), was used for the statistical analysis of the results. OS was calculated from date of diagnosis to date of last contact. Moreover, survival was also calculated from date of sample collection to date of last contact. Categorical variables were compared by chi-squared test and continuous variables were compared by Mann-Whitney test or Kruskal-Wallis test where appropriate. All $p$-values were doublesided. Survival analysis was performed using the Kaplan-Meier method and log-rank statistics to test for survival correlations.

\section{Results}

Seventy-two patients with CLL were included in the study. There was a male predominance (male to female ratio: 1.48) and the median age was 70 (range=37-91) years. Sample 
Table II. Polymorphisms and mutations of TP53 detected.

\begin{tabular}{|c|c|c|c|c|c|}
\hline Codon change & Amino acid & Exon/intron position & dbSNP & Gene position & Result, N (\%) \\
\hline c. $215 \mathrm{C}>\mathrm{G}$ & P72R & Exon 4 & rs 1042522 & 16.397 & $71(98.6)$ \\
\hline c. $375+109 \mathrm{~T}>\mathrm{C}$ & & Intron 4 & - & 17.666 & $1(1.4)$ \\
\hline c. $459 \mathrm{C}>\mathrm{T}$ & P153P & Exon 5 & rs 72661116 & 17.398 & $2(2.8)$ \\
\hline c. $542 \mathrm{G}>\mathrm{A}$ & $\mathrm{R} 181 \mathrm{H}$ & Exon 5 & rs 397514495 & 17.481 & $1(1.4)$ \\
\hline c. $.578 \mathrm{~A}>\mathrm{T}$ & H193L & Exon 6 & rs786201838 & 17.598 & $1(1.4)$ \\
\hline c. $584 \mathrm{~T}>\mathrm{C}$ & $\mathrm{I} 195 \mathrm{~T}$ & Exon 6 & rs760043106 & 17.604 & $1(1.4)$ \\
\hline c. $.587 \mathrm{G} / \mathrm{A}$ & R196Q & Exon 6 & - & 17.607 & $1(1.4)$ \\
\hline c. $639 \mathrm{~A}>\mathrm{G}$ & R213R & Exon 6 & rs1800372 & 17.659 & $12(14.6)$ \\
\hline c. $993+44 \mathrm{C}>\mathrm{T}$ & & Intron 8 & - & 19.060 & $1(1.4)$ \\
\hline
\end{tabular}

Reference sequences for TP53 NG_017013.2, mRNA: NM_000546.5, protein:NP_001119584.1.

Table III. Statistical correlations.

\begin{tabular}{|c|c|c|c|}
\hline Parameter & Mutated TP53 & Wild-type TP53 & $p$-Value* \\
\hline Median age (range), years & $68(37-76)$ & $72(49-91)$ & 0.335 \\
\hline Gender (male/female) & 3.5 & 1.16 & 0.071 \\
\hline Stage (at diagnosis), N (\%) & & & 0.022 \\
\hline A & 5 & 29 & \\
\hline B & 6 & 16 & \\
\hline $\mathrm{C}$ & 8 & 8 & \\
\hline Stage (at sample collection), N (\%) & & & 0.090 \\
\hline $\mathrm{A}$ & 5 & 25 & \\
\hline $\mathrm{B}$ & 4 & 15 & \\
\hline $\mathrm{C}$ & 10 & 13 & \\
\hline Median peripheral blood lymphocyte count (range), $\times 10^{9} / 1$ & $19.2(3.0-193.8)$ & $15.2(1.4-131.0)$ & 0.765 \\
\hline Median hemoglobin (range), g/dl & $13.2(9.0-16.1)$ & $13.3(8.3-17.9)$ & 0.816 \\
\hline Median platelet count (range), $\times 10^{9} / 1$ & $150(30-257)$ & $171(52-472)$ & 0.400 \\
\hline Median LDH/ULN (range) & $1.2(0.7-3.1)$ & $1.1(0.6-7.5)$ & 0.422 \\
\hline Median $\beta 2$-microglobulin/ULN (range) ${ }^{\dagger}$ & $2.4(0.2-3.1)$ & $2.7(0.8-11.9)$ & 0.276 \\
\hline
\end{tabular}

LDH: Lactate dehydrogenase; ULN: upper limit of normal. *Two-sided.

collection was performed at diagnosis in $25(34.7 \%)$ cases and during the disease course in the rest $(65.3 \%)$. Forty-six (63.9\%) patients were treatment-naïve. The patients' epidemiological characteristics, stage of disease at diagnosis and at sample collection and blood count values are given in detail in Table I. FISH analysis for the detection of $17 \mathrm{p} 13$ deletion had been performed in $28(39.9 \%)$ patients, according to common clinical practice. Only two $(7.1 \%)$ of the tested patients had $17 \mathrm{p} 13$ deletion. Because of the very low rate of $17 \mathrm{p} 13$ deletion, no statistical significant correlations with prognosis were found. One of the patients with $17 \mathrm{p} 13$ deletion also carried a TP53 mutation (c.639A >G, rs1800372). This was a 65-yearold male with stage $\mathrm{C}$ disease that progressed to Richter's syndrome and who had an OS of 117 months. The second patient with $17 \mathrm{p} 13$ deletion was a 77 -year-old man with stage A disease who did not carry any TP53 mutation and showed no progression over a period of 98 months of follow-up.
Almost all $(n=71,98.6 \%)$ patients carried the polymorphic site encoding for arginine at the residue 72 of exon 4 , c. $215 \mathrm{C}>\mathrm{G}$ (p.Pro72Arg, rs1042522). Forty-seven of them $(47 / 72,66.2 \%)$ carried the polymorphic site in homozygosity (Arg/Arg) and 24 (33.8\%) in heterozygosity (Pro/Arg). The presence of the polymorphism in homozygosity was not correlated to any of the epidemiological and hematological characteristics of the patients, nor to OS. No correlation was found between this polymorphism and the incidence of TP53 mutation $(p=0.961)$. Moreover, the survival of patients carrying a TP53 mutation was not affected by the concomitant presence of this polymorphism $(p=0.145)$.

Mutation analysis revealed that $19(26.4 \%)$ patients carried a mutation of TP53. The detected mutations were as follows: c.639A $>\mathrm{G}$ [rs1800372] in $12(16.7 \%)$ patients, c.459C $>\mathrm{T}$ [rs72661116] and c.542G $>\mathrm{A}$ [rs397514495] in exon 5 in two (2.8\%) and one (1.4\%) patient, respectively, and c.584T>C 
[rs760043106] and c.578A $>\mathrm{T}$ [rs786201838] in exon 6 in one (1.4\%) patient each. One new mutation was detected in exon 6 , c. $587 \mathrm{G}>\mathrm{A}$. Moreover, another two mutations in introns were detected: c. $375+109 \mathrm{~T}>\mathrm{C}$ in intron 4 , and c.993+44 C>T in intron 8 , in one (1.4\%) patient each (Table II).

One patient, in addition to the presence of the homozygote polymorphic site c. $215 \mathrm{C}>\mathrm{G}$, carried another two mutations in exon 6: c.639A $>\mathrm{G}$ [rs 1800372] in homozygosity and c.584T $>$ C [rs760043106] in heterozygosity. Moreover, two other patients were heterozygous for mutations in introns 4 and 8 in addition to the polymorphic site for arginine (p53Arg) in exon 4.

The frequent silent mutation (c.639A $>$ G, R213R) was correlated with advanced disease stage $(p=0.024)$, and was far more common in males ( 10 men, two women, $p=0.06$ ), but no correlation with OS was found.

No correlations were found between the presence of TP53 mutations and the epidemiological and hematological characteristics of the patients. There was a statistically significant correlation with the stage at diagnosis (higher stage was accompanied by higher mutation rate, $p=0.022)$, but not with the stage at sample collection $(p=0.09)$. Detailed results are shown in Table III.

OS seemed to be unaffected by the mutation status of the patients both that from diagnosis $(p=0.079)$ and that from sample collection $(p=0.336)$. None of the individual mutations detected was correlated with OS.

\section{Discussion}

The common single nucleotide polymorphism (SNP) located within the proline-rich domain of p53, at codon 72 of exon 4 (c.215C $>\mathrm{G})$, results in either a proline or an arginine residue (p.Pro72Arg). The polymorphism varies with latitude and race and is maintained at different allelic frequencies across populations (16). It has been shown that the two alleles may produce functionally-distinct proteins and that the p53Arg variant induces apoptosis markedly better than the p53Pro variant (17), while the p53Pro variant appears to induce a higher level of $\mathrm{G}_{1}$ phase arrest than the p53Arg variant (18). It has been speculated that these differences may affect response to treatment and survival in CLL. Such a speculation has not been proven (19), but it has been reported that the presence of the polymorphism is associated with an increased incidence of TP53 mutation (20). In our cohort of patients, the detection of the polymorphic site encoding arginine in homozygosity or heterozygosity was very high (only one patient was Pro/Pro, 24 were Arg/Pro and 47 were Arg/Arg), higher than any other reported rate to date. However, we did not find any correlations of the polymorphism with the epidemiological and hematological characteristics of the patients, the stage or OS. Moreover, the presence of the polymorphism was not correlated with an increased incidence of TP53 mutations.

All detected mutations except for c.587G $>\mathrm{A}$ are wellcharacterized by previous researchers and the relevant information was obtained from the NCBI Search database.

The most frequently detected mutation was c.639A $>\mathrm{G}$ [rs 1800372]. This is a silent mutation at exon 6, detected in Li-Fraumeni syndrome and hereditary cancer-predisposing syndrome, and is considered of benign clinical significance. This mutation was detected in $12(16.7 \%)$ patients and was correlated with an advanced disease stage, but not with OS, a result that is in accordance with the benign nature of the mutation as given in the NCBI database.

None of the other mutations detected were correlated to the stage or the prognosis of the disease. In detail, the pathogenic c. $542 \mathrm{G}>\mathrm{A}$ mutation was found in a male patient with stage A disease that had not progressed during the follow-up period (26 months). The c.375G $>\mathrm{T}$ mutation of uncertain significance was detected in a 73-year-old male patient with stage B disease and no progression for 77 months. The pathogenic c.584T $>\mathrm{C}$ mutation was detected in a 72-year-old male patient with stage $\mathrm{C}$ disease and an OS of 92 months (27 months from the detection of the mutation). The same patient also carried c.639A $>$ G. The deemed benign c. $459 \mathrm{C}>\mathrm{T}$ mutation was detected in a 62-year-old male patient with stage A disease and no progression during a follow-up period of 41 months, as well as in an 81-year-old male patient with stage $\mathrm{C}$ disease and an OS of 10 months. The likely pathogenic c.578A $>\mathrm{T}$ mutation was detected in a 65 -year-old female patient with stage B disease and no progression from diagnosis for a total of 86 months. c. $993 \mathrm{C}>\mathrm{T}$, a mutation of uncertain significance was detected in a 68 -year-old female patient with stage B disease and no progression for 106 months. Finally, a 42-year-old man carried the new mutation c. $587 \mathrm{G}>\mathrm{A}$, which is probably pathogenic since another change at the same site (c. 587G $>C$, rs 483352697 ) has been correlated to hereditary cancer-predisposing syndrome according to the lats from the NCBI database. Although the presence of a mutation was correlated with a higher disease stage, this correlation was not accompanied by a survival disadvantage.

In conclusion, our results lean towards the absence of clinical significance of TP53 mutations when not accompanied by $17 \mathrm{p} 13$ deletion and this conclusion is in accordance with several research studies in the field. Therefore, the clinical significance of TP53 mutations is still a matter of debate, and we need larger studies, or a metaanalysis of the existing ones, in order to reach an unequivocal conclusion. The clinical implication of the results of the studies so far is that in order to assess for TP53 abnormalities, the use of both FISH to detect 17p13 deletion and gene sequencing is recommended in order for the complete range of TP53 abnormalities to be covered (21). 


\section{Conflicts of Interest}

The Authors declare that they have no conflict of interest in regard to this study.

\section{References}

1 Döhner H, Fischer K, Bentz M, Hansen K, Benner A, Cabot G, Diehl D, Schlenk R, Coy J and Stilgenbauer S: p53 gene deletion predicts for poor survival and non-response to therapy with purine analogs in chronic B-cell leukemias. Blood 85: 1580-1589, 1995.

2 Montserrat E,Moreno C, EsteveJ, Urbano-Ispizua A, Giné E and Bosch F: How I treat refractory CLL. Blood 107: 1276-1283, 2006.

3 Foà R, Del Giudice I, Guarini A, Rossi D and Gaidano G: Clinical implications of the molecular genetics of chronic lymphocytic leukemia. Haematologica 98(5): 675-685, 2013.

4 Fabbri G, Khiabanian H, Holmes AB, Wang J, Messina M, Mullighan CG, Pasqualucci L, Rabadan R and Dalla-Favera R: Genetic lesions associated with chronic lymphocytic leukemia transformation to Richter syndrome. J Exp Med 210(11): 22732288, 2013.

5 Rossi D, Cerri M, Deambrogi C, Sozzi E, Cresta S, Rasi S, De Paoli L, Spina V, Gattei V, Capello D, Forconi F, Lauria F and Gaidano G: The prognostic value of TP53 mutations in chronic lymphocytic leukemia is independent of Del17p13: implications for overall survival and chemorefractoriness. Clin Cancer Res 15(3): 995-1004, 2009.

6 Rossi D and Gaidano G: The clinical implications of gene mutations in chronic lymphocytic leukaemia. Br J Cancer 114(8): 849-854, 2016.

7 Oscier DG, Gardiner AC, Mould SJ, Glide S, Davis ZA, Ibbotson RE, Corcoran MM, Chapman RM, Thomas PW, Copplestone JA, Orchard JA and Hamblin TJ: Multivariate analysis of prognostic factors in CLL: clinical stage, $I G V H$ gene mutational status, and loss or mutation of the $p 53$ gene are independent prognostic factors. Blood 100(4): 1177-1184, 2002.

8 Dong HJ, Zhou LT, Zhu DX, Wang DM, Fang C, Zhu HY, Zhuang Y, Miao KR, Xu W and Li JY: The prognostic significance of TP53 mutations in Chinese patients with chronic lymphocytic leukemia is independent of $\operatorname{del}(17 \mathrm{p} 13)$. Ann Hematol 90(6): 709-717, 2011.

9 Dicker F, Herholz H, Schnittger S, Nakao A, Patten N, Wu L, Kern W, Haferlach T and Haferlach C: The detection of TP53 mutations in chronic lymphocytic leukemia independently predicts rapid disease progression and is highly correlated with a complex aberrant karyotype. Leukemia 23(1): 117-124, 2009.

10 Chiaretti S, Tavolaro S, Marinelli M, Messina M, Del Giudice I, Mauro FR, Santangelo S, Piciocchi A, Peragine N, Truong S, Patten N, Ghia EM, Torrente I, De Propris MS, Nanni M, Lawrence J, Guarini A and Foà R: Evaluation of TP53 mutations with the AmpliChip p53 research test in chronic lymphocytic leukemia: correlation with clinical outcome and gene expression profiling. Genes Chromosomes Cancer 50(4): 263-274, 2011.

11 Malcikova J, Smardova J, Rocnova L, Tichy B, Kuglik P, Vranova V, Cejkova S, Svitakova M, Skuhrova Francova H, Brychtova Y, Doubek M, Brejcha M, Klabusay M, Mayer J, Pospisilova $\mathrm{S}$ and Trbusek M: Monoallelic and biallelic inactivation of TP53 gene in chronic lymphocytic leukemia: selection, impact on survival, and response to DNA damage. Blood 114(26): 5307-5314, 2009.
12 Trbusek M, Smardova J, Malcikova J, Sebejova L, Dobes P, Svitakova M, Vranova V, Mraz M, Francova HS, Doubek M, Brychtova Y, Kuglik P, Pospisilova S and Mayer J: Missense mutations located in structural p53 DNA-binding motifs are associated with extremely poor survival in chronic lymphocytic leukemia. J Clin Oncol 29(19): 2703-2708, 2011.

13 Gonzalez D, Martinez P, Wade R, Hockley S, Oscier D, Matutes E, Dearden CE, Richards SM, Catovsky D and Morgan GJ: Mutational status of the TP53 gene as a predictor of response and survival in patients with chronic lymphocytic leukemia: results from the LRF CLL4 trial. J Clin Oncol 29(16): 22232229, 2011.

14 Zenz T, Häbe S, Denzel T, Mohr J, Winkler D, Bühler A, Sarno A, Groner S, Mertens D, Busch R, Hallek M, Döhner H and Stilgenbauer S: Detailed analysis of p53 pathway defects in fludarabine-refractory chronic lymphocytic leukemia (CLL): dissecting the contribution of $17 \mathrm{p}$ deletion, TP53 mutation, p53p21 dysfunction, and miR34a in a prospective clinical trial. Blood 114(13): 2589-2597, 2009.

15 Zenz T, Vollmer D, Trbusek M, Smardova J, Benner A, Soussi T, Helfrich H, Heuberger M, Hoth P, Fuge M, Denzel T, Häbe S, Malcikova J, Kuglik P, Truong S, Patten N, Wu L, Oscier D, Ibbotson R, Gardiner A, Tracy I, Lin K, Pettitt A, Pospisilova S, Mayer J, Hallek M, Döhner $\mathrm{H}$ and Stilgenbauer S: TP53 mutation profile in chronic lymphocytic leukemia: evidence for a disease-specific profile from a comprehensive analysis of 268 mutations. Leukemia 24(12): 2072-2079, 2010.

16 Sjalander A, Birgander R, Kivela A and Beckman G: p53 polymorphisms and haplotypes in different ethnic groups. Hum Hered 45(3): 144-149, 1995.

17 Dumont P, Leu JI, Della Pietra AC 3rd, George DL and Murphy M: The codon 72 polymorphic variants of p53 have markedly different apoptotic potential. Nat Genet 33(3): 357-365, 2003.

18 Pim D and Banks L: $p 53$ polymorphic variants at codon 72 exert different effects on cell cycle progression. Int J Cancer 108(2): 196-199, 2004.

19 Sturm I, Bosanquet AG, Hummel M, Dörken B and Daniel PT: In B-CLL, the codon 72 polymorphic variants of p53 are not related to drug resistance and disease prognosis. BMC Cancer 18;5: 105, 2005.

20 Bilous NI, Abramenko IV, Chumak AA, Dyagil IS and Martina ZV: TP53 codon 72 single nucleotide polymorphism in chronic lymphocytic leukemia. Exp Oncol 36(4): 258-261, 2014.

21 Pospisilova S, Gonzalez D, Malcikova J, Trbusek M, Rossi D, Kater AP, Cymbalista F, Eichhorst B, Hallek M, Döhner H, Hillmen P, van Oers M, Gribben J, Ghia P, Montserrat E, Stilgenbauer S and Zenz T: ERIC recommendations on TP53 mutation analysis in chronic lymphocytic leukemia. Leukemia 26(7): 1458-1461, 2012.
Received February 28, 2017

Revised March 19, 2017

Accepted March 21, 2017 